\title{
Clothing acculturation of North Korean female defectors in South Korea
}

\author{
Jeyeon $\mathrm{JO}^{1}$ and Jisoo $\mathrm{Ha}^{2^{*}}$ (I)
}

\section{${ }^{*}$ Correspondence:}

jisooha@snu.ac.kr

${ }^{2}$ Department of Textiles,

Merchandising and Fashion

Design, Seoul National

University, 1 Gwanak-ro,

Gwanak-gu, Seoul, Republic

of Korea

Full list of author information

is available at the end of the article

\begin{abstract}
The purpose of this study is to observe how female defectors from North Korea acculturate in South Korean clothing culture and to discuss possible policies to help their cultural settlement. North Korean defectors can experience culture shock and feel much pressure to adopt new lifestyle in terms of South Korean mode of fashion. Therefore, this research examines cultural points where NK female defectors recognize differences between two clothing cultures. To this end, in-depth interview was conducted with 11 participants. Researchers observed three types of clothing acculturation and drew a paradigm model that depicts the phenomenon of clothing acculturation of North Korean female defectors. Lastly, this study discussed about three possible policy suggestions based on the observed acculturation strategies by acculturation types. This study involves academic implications for investigating clothing acculturation by an immigrant group in a new society in a broad sense. There is a limit on this research that there can be some biased responses from participants because of the uniqueness of the group.
\end{abstract}

Keywords: Clothing, Acculturation, North Korean defector, Female, Fashion, South Korea

\section{Introduction}

One of the main topics in acculturation is a reaction of immigrant group to clothing culture of the new society (Berry 1997). Clothing culture of a society is connected to visual tradition and cultural custom (Johnson et al. 2014; Yen and Hsu 2017), so it affects the members' appearance consequently (Jung and Hwang 2016). When immigrants enter into a new society, their appearance-not only physical attributes but also their clothesmakes a distinguishable or sometimes subtle distinction between new settlers and natives. The immigrants' behaviors of selection and compromise between two clothing cultures are related to factors such as aesthetic taste, consumption value, and clothing norms. The purpose of this research is to observe North Korean female defectors' clothing acculturation process in South Korea so that discussion about effective supports for their cultural settlement can be conducted. It is revealed that North Korean defectors typically undergo the acculturation period in South Korea because of cultural differences of two Koreas. Therefore, this research conducts in-depth interviews to investigate the whole clothing acculturation process including the topics like the attitude toward South Korean clothing culture, assimilation pressure, and the ways to adjust South Korean

(c) The Author(s) 2018. This article is distributed under the terms of the Creative Commons Attribution 4.0 International License (http://creativecommons.org/licenses/by/4.0/), which permits unrestricted use, distribution, and reproduction in any medium, provided you give appropriate credit to the original author(s) and the source, provide a link to the Creative Commons license, and indicate if changes were made. 
fashion trend in accordance to personal values. Lastly, possible policies to help clothing acculturation of them would be discussed.

\section{Literature review}

\section{Clothing acculturation}

Acculturation can be defined as 'changes and results by continuous and direct contact of different cultures (Redfield et al. 1936).' To understand acculturation phenomenon deeply, Berry (1997) suggested two-dimensional acculturation model which present four acculturation types classified by directivities to immigrant's native culture and new society's culture: Integration type which means preference to both cultures, Assimilation type which is accepting only new culture, Separation type sticking to only native culture, and Marginalization type denying both culture. As one of major parts of a culture, clothing culture includes fabric-made body-covers, and all kind of items that construct human appearance like ornamentation, wig or perfume (Kim 2004; Essel and Kemevor 2016), and clothing acculturation herein refers to both attitudes and behaviors of immigrants toward the clothing culture of a new society with all items that organizes personal appearance (Chae 2003). Previous studies revealed that clothing acculturation appears in the gaps of clothing norm, aesthetic standard, body image, ethnic identity, and shopping propensity between immigrants and new society.

In terms of social clothing norms, immigrants tended to avoid potential conflicts by conforming to social rules and obeying it. This is not based on personal characteristic, but it is more helpful to survive in the new society's politic and economic environment (Padilla and Perez 2003). Weinstock (1963) observed that Hungarian immigrants who have more specialized jobs receive higher pressure to wear clothes and to pronounce words in 'American style.' Inglessis (2008) found that Hispanic females in America stated that they learn American clothing norms in church, school, or in office and when they encounter a problem regarding clothing cultural difference, they follow how their mothers behave at the same point. Those cases show that immigrants experience inner or outer conflicts on constructing their appearance.

Aesthetic taste and body image can be a part of socio-cultural stereotypes. New settlers encounter and interact with social stereotypes on a standard of beauty, so they choose to accept or refuse by consuming clothes (Luedicke 2011). Sandikci et al. (2006) showed how women moving to urban from suburban feel difficult to understand and accept urban aesthetic concepts about body, appearance, and body exposure. In their research, the women from suburban resolve inner conflicts by wearing some kind of accessories. (Ger and stergaard 1998) also observed that Turkish-Danish teenagers in Denmark subtly recognized which kind of details in a cloth could make them look like more 'Turk' or 'Danish'. The differentiating points are subtle, like how tight the pants are, so they selected appropriate types by situations. Hispanic females in America also perceived the difference of fashion styles. They used some unique factors from their native clothing culture because they don't want to follow monotonous-looking American fashion style (Inglessis 2008). When it comes to body image, some researchers argued that immigrant groups like Chinese, European males and Hispanic males in America are under the influence of American ideal body or beauty image. This triggers acculturation stress or body dissatisfaction in some cases (Cheng 2000; Warren 2008; Warren and Rios 2013). 
In addition, ethnic identity is also one of the most influential factors in clothing acculturation. Immigrant's self-awareness about ethnic identity has an association with ethnic group's influence as a fashion reference group and frequency to wear ethnic costumes (Forney 1980; Forney and Rabolt 1986). In the research on acculturation of Indian immigrants in United States, Upchurch (2008) revealed the correlation between preference to ethnic costume and acculturation level. Asian immigrant women in South Korea also apply their ethnic identity into their clothes, especially under a condition of low social interaction and low satisfaction of life (Jun 2015). Acculturation is associated with personal shopping style. (Shim and Chen 1996) examined the relationship between acculturation level and shopping habit for American Chinese. As a result, they observed that low participation in American culture group shows more inactive shopping habit than in highly participating group.

Therefore, North Korean female defector, as immigrants group in South Korea also would have experiences about different clothing norm and gap of two fashion styles. Furthermore, regarding to two Korea' traditional costumes called Han-bok, they can their own preference to one of them according to ethnic identity. Lastly, they can show different shopping behaviors or shopping reference groups in accordance with acculturation types.

\section{North Korean defectors and current clothing culture of North Korea}

North Korean defectors mean the people who were born in North Korea, but left their home and moved to South Korea. The population of them reached 29,000 in the first half of 2016, $80 \%$ of which are women (The Ministry of Unification 2016a). Many researchers focus on their experiences in North Korea or period in which escape occurs as well as harmful impacts on their mental health. North Korean defectors experience emotional difficulties because of different lifestyles (18.2\%), different language (12.5\%), or isolation (10.4\%) (Jeon 1997). Another research (Park 1998) claimed that North Korean female defectors mentioned culture shock on westernized clothing and food culture.

Until now, North Korea has closed and unilateral system that the communist party has a substantial authority to produce and distribute properties. From 1950s, North Korean government shapes an identical ideality for permanent dictatorship and implements clothing policies to support it. The female ideal identity offered by North Korean government is, for example, a female who is loyal to the party and government or a female conducting communistic idealism (Lee 2004), and it is promoted by 'Socialism Lifestyle' policy which defines every detail of people's daily life including clothing. Kwon (2016) also said that NK government has produced an image of an ideal female laborer in communism by compelling a specific kind of hairstyle or clothing. Furthermore, to inhibit the influence of western capitalism, NK government restricts western-style clothing such as jeans, mini skirt or bell-line pants, and forces female to wear Korean traditional costume at some political events. Under the government's restriction most of clothes in NK are simple-looking, not colorful, and rarely changing. Meanwhile, according to the testimony of NK defectors, most of North Koreans have just 1 or 2 clothing for poor economic condition, so they usually wear same clothes every day (Rhee et al. 1997a, b). According to Rhee et al. (1999), North Korean ordinary people can buy 1.32 clothes in a year on average. Even though they have not enough clothes, $70 \%$ of NK defectors said many NK people follow a fashion trend in North Korea. However, North Korean 
fashion trend is quite different. They said that there is only one fashion trend at a time, which almost everyone follows together. The fashion trend usually starts from near Chinese border region or Pyong-yang, and spreads through the whole country slowly. In the changes of the fashion trend, only the minimum change happens in the boundary of simple style (Kim 2016).

North Korean defectors in South Korea usually follow South Korean cultural lifestyle when they experience internal conflict due to cultural difference. A study on North Korean female defectors shows that they are mentally shrunk in South Korea and forced to be identified as North Korean defectors by situations (Cho and Jeon 2005). Furthermore, they could be under a potential pressure to assimilate into South Korean culture. Kim (2016) argued that North Korean defectors do not prefer North Korean fashion style and inclined to be concerned about identity disclosure based on fashion styles. However, there are other cases like those who had been an upper class in North Korea and don't be embarrassed by South Korean westernized clothing culture.

\section{Methods}

\section{Design}

In this research, in-depth interview was conducted with semi-constructed questionnaires. Researchers recruited interview participants by conducting pre-survey on North Korean defector's online community websites. The pre-survey included 14 questions about North/South Korean clothing culture, 2 questions for demographic information and 1 question to ask to participate in in-depth interview. The online pre-survey had been conducted from October 4, 2016 to November 16, 2016. In total, 30 random North Korean female defectors in South Korea participated in the pre-survey, and 11 of them showed will to join to the in-depth interview. Semi-constructed questionnaire for indepth interview was made of two parts: first, since every interviewee had participated in the pre-survey, researchers used pre-survey response of each participant. Second, Researchers prepared additional questionnaires regarding their experiences about clothing culture of two Koreas and ideal fashion image in daily life. Both pre-survey and semiconstructed questionnaires for interview were based on previous researches related to acculturation and NK defectors (Forney 1980; Forney and Rabolt 1986; Park 1998; Shim and Chen 1996; Alkhazraji et al. 1997; Swaidan et al. 2006; Inglessis 2008; Keum 2015; Sohn 2013; Kim 2016). Every interview was transcribed under the agreement of the interviewees and analyzed based on grounded theory.

\section{Details}

11 female interviewees born in North Korea participated in the in-depth interview. Before starting both pre-survey on online and in-depth interview, this research had been approved by from Seoul National University Institutional Review Board. Researchers explained enough about ethical considerations with approved consent before starting every interview. Especially, voice recording was conducted only under the conditions the interviewee allowed, and when the interviewee denied, researchers just transcribed by computer. Every interview was conducted in the place where interviewee wanted at November 2016. Interview time was from $1 \mathrm{~h}$ to $1 \mathrm{~h}$ and a half. Researchers didn't ask personal information in North Korea excessively, for North Korean defectors still tend 
to be highly suspicious because of dreadful experiences in North Korea overwhelming them (Keum 2015). Every interviewee received proper reward for the interview. After interview, researchers transcribed voice records, and divided, reconstructed, selected and interpreted transcribed data following the process of grounded theory analysis: open coding, axial coding and selective coding. Two other fellow researchers with doctoral degrees who are proficient in adopting grounded theory analysis supervised the analysis process and results. They confirmed credibility, fittingness, audit-ability and confirmation of the analysis. Personal information of interviewees was never revealed except researchers, nor used for another use. Voice record files and transcribed data were saved in secured storing place.

\section{Results}

\section{Open coding}

By analyzing transcribed interview data following open coding analysis, researchers found 48 codes, 24 subcategories, and 6 categories. Each category was named 'Restricted Clothing Culture of North Korea,' 'Personal Economic Condition in North Korea, 'Culture Shock in South Korea,' 'Fashion Sensitivity', 'Self-identity' and 'Various Clothing Acculturation Behaviors.'

\section{Restricted clothing culture of North Korea}

Every interviewee testified that North Korean clothing culture is under a stronglyrestricted condition. North Korean government prohibits clothes with English letter, dyed hair or jeans because they symbolize capitalism which is a threat to North Korea's socialism. NK government also restricts colorful clothes, so interviewees could wear only clothes in navy, dark green, black, or gray colors in North Korea. Furthermore, they said North Korean people think that everyone must look similar. If someone wears different kind of clothes comparing to others, people would blame the person because of the uniqueness. Under the long reign of terror of NK government, NK people tend to not only avoid looking different to other, but also impose the strict standard to others. In quantity, there were not enough clothes both in house and in the market. Because of poor and tightly controlled economy, most of NK people have just one or two clothes. Many interviewees said because they had only two clothes, they wore one in weekdays, and another in weekend. In the market, they didn't have to consider among many fashion products because there was no option except one or two types of clothes.

"There are many strict norms for clothes in North Korea. The clothes with English letters, dyed hair, jeans ... because those clothes symbolize capitalism, not North Korean socialism." (Participant I).

"If someone wears unique clothes, people blame the person because he (or she) looks different. They think everyone must look similar." (Participant C).

"I wear just the same clothes for the whole week. Only rich people have four or five clothes. Most people have only two or three in just simple colors." (Participant D).

"Everyone wears similarly because there are a few options available." (Participant A). 


\section{Personal economic condition in North Korea}

However, few of the interviewee said they could experience an abundant consumption life even under the restricted condition. Some participants who had been rich in North Korea stated that they could wear expensive Japanese, Chinese and South Korean clothes and foreign luxury cosmetics. They even sometimes ordered a cloth which looks like what they saw in South Korean drama. Meanwhile, ordinary people had just one or two clothes to endure a year. The gap of personal economic gap between people in high class and general public was huge in North Korea.

"I have been interested in fashion since I lived in North Korea. I wore Japanese clothes or some unique clothes imported from China, and even from South Korea. It was okay if I cut the label of South Korean clothes." (Participant C).

\section{Culture shock in South Korea}

North Korean female defectors mentioned a remarkable difference between two clothing cultures which had made them embarrassed at the beginning of settlement in South Korea. They wasn't familiar with a certain clothing norm of South Korea regarding wedding ceremony, funeral, or at the working place. Most of them stated that they were shocked by level of women's body exposure. Because of conservative policy of North Korean government, they couldn't accept South Korean standard on female's body exposure. Furthermore, under the limited and highly restricted clothing culture of North Korea, interviewees didn't have enough personal fashion styling or shopping experience in North Korea. Therefore when they entered in South Korea, they could help confronting a high wall of South Korean fashion trend. Some said they were like a fashion terrorist. Destroyed jeans or rugged knit wear are also what they couldn't accept easily, because those are symbols of poverty in North Korea. They also found differences in shopping culture or South Korean traditional costume.

"For the first time I was in a wedding in South Korea, I felt embarrassed because I did not dress up at all." (Participant K).

"North Koreans are unfamiliar with colorful clothes in South Korea, because they had been never allowed to buy those kinds of clothes. Thus, they could be considered as fashion terrorists in South Korea." (Participant C).

"I heard many times that I was not dressed well at the early settlement. I just bought clothes adorable without considering whether it fits to me." (Participant B).

"North Korean Han-bok is light and soft, but South Korean is stiff and too formal." (Participant H).

\section{Fashion sensitivity}

Personal level of fashion sensitivity varies by individual. When researchers asked about interest on fashion trend in South Korea, some participant said they are always passionate to learn and accept new fashion trends. They also enjoy shopping both alone or with friends. At the same time, they tend to be conscious of other people's opinion on them. 
They want not to look like a North Korea defector in South Korea, because they think North Korea defectors are usually regarded as a fashion terrorist. On the other hand, other interviewees don't care about others' judgment on their fashion style. They don't follow South or North Korean fashion trend. They just buy cheap clothes or check only if it fits their body.

"I love shopping and have a lot of interest in fashion. Though I have many clothes, I always buy more pretty clothes by giving up other things to have." (Participant B).

"My husband said that my fashion style is quite out of style, but I don't care about it. What considers to me is just fitness on my own body." (Participant K).

\section{Self-identity}

Three different type of self-identity were observed in the interviews. First, many interviewees want to be shown to others like a native South Korean. They try to hide an identity as a North Korean defector, and want to live like an ordinary South Korean. They think themselves as a complete South Korean. Second group is skeptical about self-identity matters because they were disappointed at two Koreas. Even though they defected from North Korea to find a hope in South Korea, in cases where they experienced a kind of discriminations in South Korea, they don't like both North and South Korea. Last group also testified bad experiences in South Korea, but they have more mature and independent attitudes. They admitted they should embrace two types of self-identity as a native North Korean and a citizen of South Korea. They don't depend on one culture too much, but try to find and maintain value of each Korea.

"I don't' want to look like a person from North Korea. I just want to be a real South Korean." (Participant B).

"Even though I wear like South Koreans, I could not change totally into a native South Korean. I don't care about how others think."(Participant I).

"At first, I made much effort to look like a South Korean in terms of fashion or language. However, once I realized my identity and my personality, I was satisfied with being either a South Korean or a North Korean." (Participant D).

\section{Various clothing acculturation behaviors}

To deal with culture shock in South Korea, North Korea female defectors showed various kind of clothing acculturation behaviors. First of all, regarding to clothing norms of South Korea, almost all participant stated that they are trying to accept general clothing norms for certain situations such as wedding, funeral, school, or working place. They said they learn the norms from TV, friends or Internet. However, about half of the interviewees denied accepting South Korean standard on body exposure.

"North Koreans usually don't wear black clothes in a funeral. I learned this through watching TV drama in South Korea." (Participant F). 
"This regards much body exposure. I was so shocked for the first time particularly in summer. I think it's abnormal and even unacceptable to expose shoulder or belly."

(Participant K).

About fashion styling, some people said they are learning South Korean fashion style and applying it their own life to look more like a native South Korean, even though others don't want to follow South Korean fashion trend and still have aesthetic tastes of North Korea.

"I search South Korean fashion trend online, and learn fashion from TV. Furthermore, I watch South Korean young ladies' fashion style in the street to follow the trend." (Participant A).

"I try to learn South Korean cosmetic style, but my old habit habituated since living in North Korea is hard to change." (Participant J).

When they go shopping, many preferred to go alone because they not only have different taste with South Korean but also think that there's nothing to learn from North Korean defectors. However, few showed dependence on North Korean defector group to share information about clothing culture in South Korea.

"I don't think the friends (NK female defectors) have something to learn, because they are also beginning to become familiar with South Korean culture like me." (Participant $H)$.

"I usually receive new information from NK defector friends about the place selling cheap clothes and other stuff." (Participant F).

Lastly, most of interviewee said South Korean traditional costume is more beautiful than NK's because of high quality fabric, diversity of design and colorfulness. On the other hand, some missed North Korean traditional costume for it has its own unique silhouette and softness of the fabric.

"South Korean Han-bok is better because the quality of the fabric is luxurious and colorful." (Participant D).

"I prefer North Korean Han-bok. North Korean Han-bok style looks more beautiful in my viewpoint." (Participant F).

Based on the two-dimensional acculturation model of Berry (1997), interviewees with various kinds of clothing acculturation behaviors can be classified into three types; Assimilation, Integration, and Marginalization. For Assimilation type, interviewee A, B, $\mathrm{C}$, D, and E who preferred only South Korean clothing culture and don't want to maintain North Korean clothing culture selected. They also showed high fashion sensitivity and South Korean-oriented identity in the interview. For Integration type, participant F, G, H, I, and J selected because they show preference parts of both culture. Integration type interviewees also have independent self-identity which admits both nationalities. They didn't show a certain type of fashion sensitivity. Lastly interviewee $\mathrm{K}$ only was classified as Marginalization type for they denied accepting both two clothing cultures. They usually showed low fashion sensitiveness and skeptical self-identity (Table 1). 


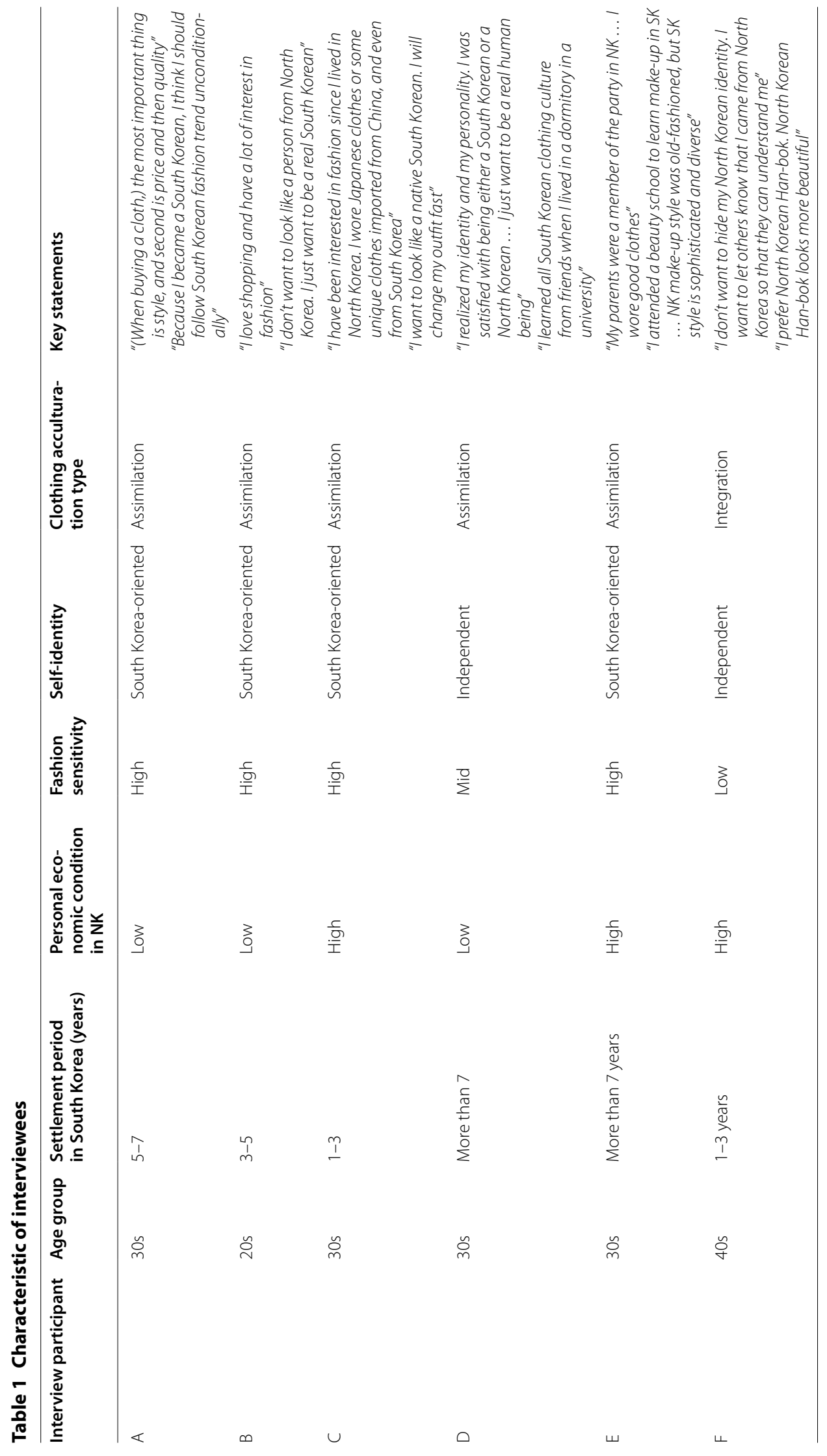




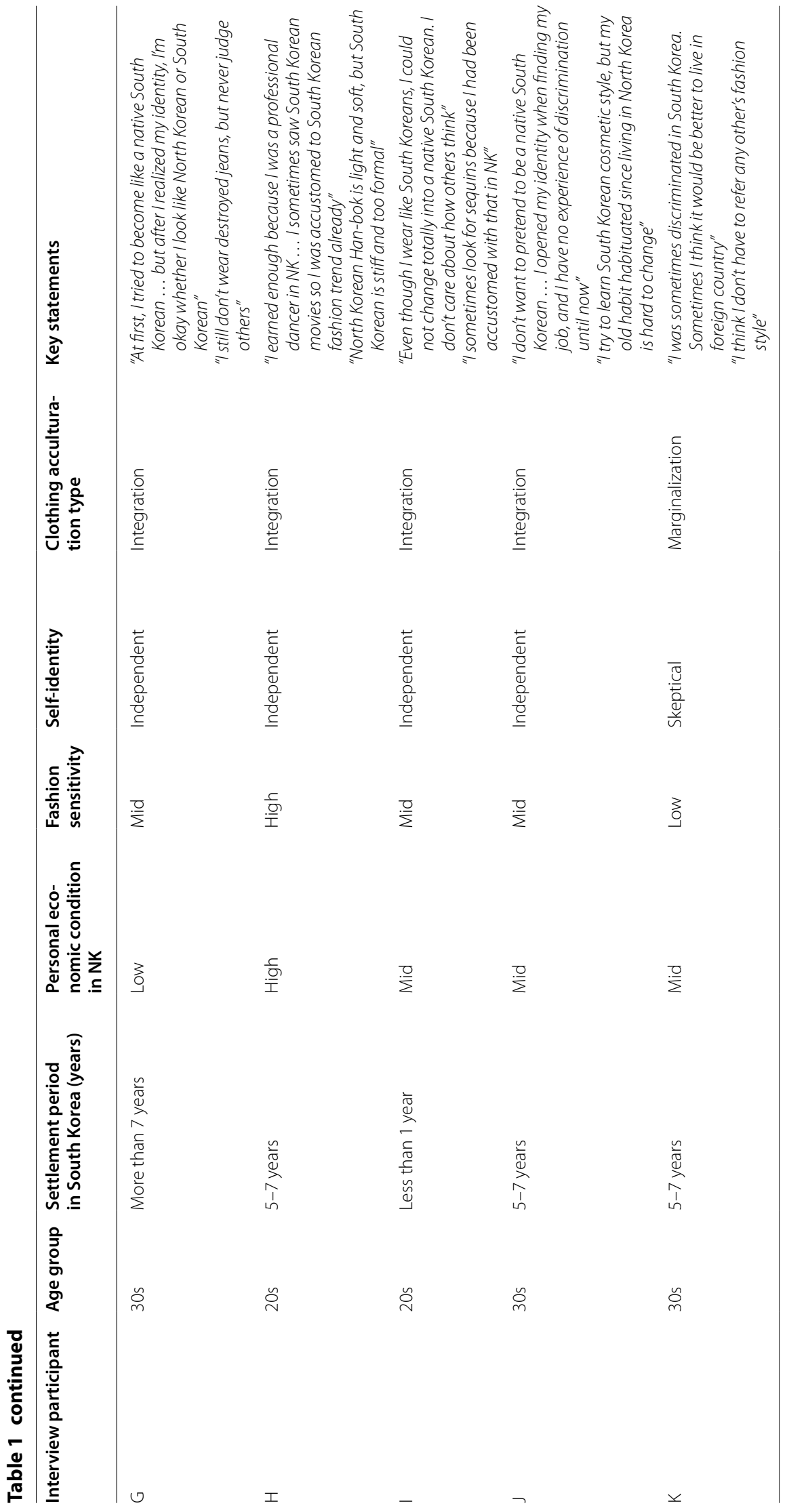




\section{Axial coding}

Researchers found the causal relationship between the categories of open coding analysis following the process of axial coding of grounded theory (Fig. 1). North Korean female defectors had lived inside of North Korean clothing culture for a long time, so they had built up their own unique clothing behavior based on that culture. Therefore, they experience quite strong culture shock when they happened to face with South Korean clothing culture which is contrary to North Korean. At this point, each interviewee's personal economic condition in North Korea, which determines contact level to foreign clothing culture, can adjust the culture shock degree.

"I earned enough because I was a professional dancer in North Korea ... I sometimes saw South Korean movies so I was accustomed to South Korean fashion trend already." (Participant H/rich in North Korea).

As a reaction to the perceived clothing cultural differences of two Koreas, they testified their various acculturation behaviors. As a source of behavior, fashion sensitivity and self-identity decide the way of behaviors individually. Those who have high fashion sensitivity tend to follow South Korean fashion trend, but those with low fashion sensitivity don't care about both.

"I have been interested in fashion when I was in North Korea ... I want to look like a native South Korean. I will change my outfit fast." (Participant C/high fashion sensitivity).

"I don't know anything about trend ... I just choose convenient clothes to work well, and I don't check how others wear." (Participant K/low fashion sensitivity).

A group who has South Korea-oriented self-identity chooses the way to accept most of South Korean clothing culture. Meanwhile, skeptical identity (Table 1) group don't show will to follow any clothing culture, and independent identity group decide to accept parts of both.

"Because I became a South Korean, I think I should follow South Korean fashion trend unconditionally." (Participant A/South Korea-oriented identity).

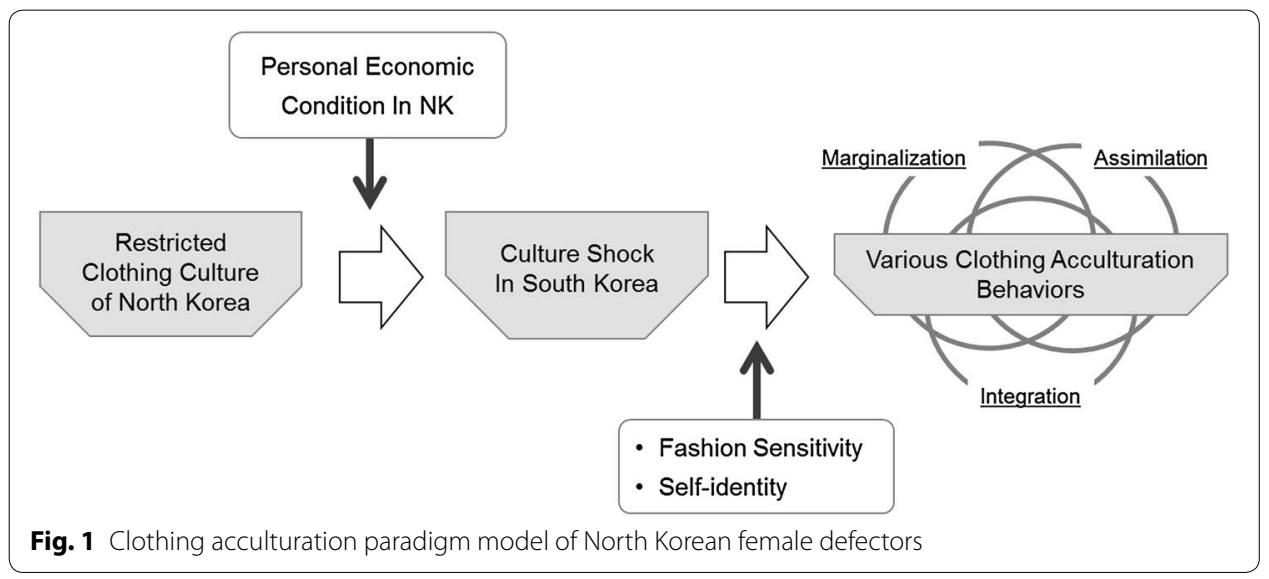


"I was sometimes discriminated in South Korea. Sometimes I think it would be better to live in foreign country." (Participant K/skeptical identity).

"I prefer North Korean Han-bok.... I want to let others know that I came from North Korea so that they can understand me. (Participant F/independent identity).

\section{Selective coding}

The purpose of grounded theory is to draw a supposable hypothesis from analysis on qualitative data by focusing on a reasonable result when there is not enough research about the topic. Researchers focused on the influence of fashion sensitivity and self-identity on classification of clothing acculturation types. Most of interviewees who showed high fashion sensitivity prefer to accept South Korean clothing culture and to remove memories of North Korean clothing culture. They consider their appearance much and want to be shown to others like a native South Korean. They try to follow South Korean fashion trend and learn most of parts of South Korean clothing culture. They never get information from North Korean defector group because they think there's nothing to learn from that group, and want to forget memories about North Korean clothing culture. Meanwhile the interviewee in Marginalization type had low fashion sensitivity, but it can't be generalized because of lack of number of case. For Integration type, interviewees showed various level of fashion sensitivity. Therefore, according to the purpose of grounded theory, this statement can be suggested first: High level of fashion sensitivity of North Korean female defector is related to Assimilation behaviors in clothing acculturation.

Secondly, self-identity is another factor deciding clothing acculturation behaviors in the result. South Korea-oriented identity makes the interviewees want to look more like a native South Korean, so they choose to accept whole South Korean clothing culture and to deny previous one totally. Interviewees who showed independent identity admitting both North and South Korean identity are mostly classified into Integration type. Even though they defected from North Korea, they remembered some good points of North Korean clothing culture such as North Korean traditional costume or fashion trend items. Because they are both good cultural learners in South Korea and good conservators of North Korean clothing culture partially, they are regarded as Integration type. Lastly, one interviewee had a skeptical attitude to identity matter because she experienced discriminations in South Korea. She denied accepting both North and South Korean clothing culture, so that she is classified to Marginalization. Therefore this statement would be supposable secondly: North Korean female defector accepts clothing culture(s) according to self-identity regarding personal nationality.

\section{Discussion}

North Korean female defectors face culture shock because of differences of two clothing cultures in South Korea. To reduce it, South Korean government offers culture education programs, but most of acculturation policies for them are prone to assimilation to make all NK defectors like native South Koreans. However, as we can see, each North Korean female defector has own level of fashion sensitivity and type of self-identity. It means that some of them can want not to become like a native South Korean. In this research, North 
Korean female defectors don't show uniform clothing acculturation behaviors based on their own fashion sensitivity and self-identity. Thus, polices that considers only assimilation type can spark social conflicts. South Korean society should understand that each North Korean defector has their own type of clothing acculturation, so they cannot make them into a stereotyped new South Korean. In the case of German unification, incorporated German government did not introduce the East German West German art culture unilaterally. Instead, it recognized mutual 'positive differences' and guaranteed art activities performed by private cultural organizations. In consequence, East German art now promotes art culture in Unified Germany and contribute to make the contemporary German culture more dynamically and profusely (Ministry of Unification 2016b). Likewise, an ideal direction for acculturation policy is to make up an integration acculturation type, which respects both cultures and accept mutual differences in an optimistic way. According to Bourhis et al. (1997), only when combinations of acculturation types of native group and immigrant group are integration-integration, assimilation-assimilation, or marginalization-marginalization, two groups would exists in harmony.

Therefore, the following policies are necessary in order to reduce possible culture shock of North Korean female defectors and to promote social integration. First, detailed instruction on South Korean fashion culture is needed in Hana-won, where North Korean defectors learn basic knowledge before they enter into the real society. It is a way to minimize culture shock they would experience soon. They need to learn some characteristics of South Korean clothing culture such as general body exposure standard or clothing norms in special situations like weddings or funerals before they start to live in the society alone. Secondly, various acculturation programs based on types of clothing acculturation should be conducted by South Korean government or private organizations. It should be added with the understanding that not every North Korean female defector has to be accustomed to South Korean fashion culture. Diverse programs like North/South Korean Han-bok wearing event, party and sharing fashion information with North Korean female group, or seminar on clothing norm about South Korean fashion trend are possible. It would be a good idea to support private organizations financially so that they can run various programs. Lastly, in the long-term perspective, it is urgent to improve attitude of South Korean society on North Korean defectors. South Koreans should understand that North Korean who crossed the border could feel strange to a new clothing culture and have a free will not to follow the South Korean fashion trend. Therefore South Korean government can promote cultural campaign to improve understanding toward each other. It can be a significant step to prepare for unification of two Koreas in a possible future.

\section{Conclusion}

This study is an exploratory research on the clothing acculturation behaviors of North Korean female defectors. Researchers conducted in-depth interviews and drew conclusions following analyzing process of grounded theory. According to the research on North Korean female defectors, every North Korean female defectors in this study testified early culture shock for the difference between the culture that they experience at North and the new culture in South. However, the degree of the shock varied according to the levels of personal economic conditions in North Korea. Participants choose 
various kinds of acculturation behaviors to react the cultural difference by individual fashion sensitivity and self-identity. Participants are classified into three types of clothing acculturation; Assimilation, Integration and Marginalization. Based on the diversity of clothing acculturation types, government and private organization's cooperation as well as both short/long-term supports are necessary. Lastly, because there was not enough previous research about this topic, researchers tried to open the way for future research by suggesting two supposable hypotheses about the relationship between fashion sensitivity and clothing acculturation type, and between self-identity regarding personal nationality and clothing acculturation type. Studies testifying these two hypotheses by quantitative method can be conducted in the future.

This research explores overall aspects of clothing acculturation of North Korean female defectors and suggested possible research topics and government policies. However, there are major limitations in this research. First of all, hypotheses suggested as main results are based on researchers' interpretation on the interviews. Researchers tried to recruit enough number of participant to generalize the finding quantitatively but couldn't, because many North Korean defectors still don't want to reveal their identity as a North Korean. Furthermore, North Korean defectors tend to have a resistance politically and emotionally against North Korean government, so they could answer partially in in-depth interview (Keum 2015). Nevertheless, the result is expected to be used as a basic database to understand clothing cultural interactions between many cultural groups especially in Korean peninsula.

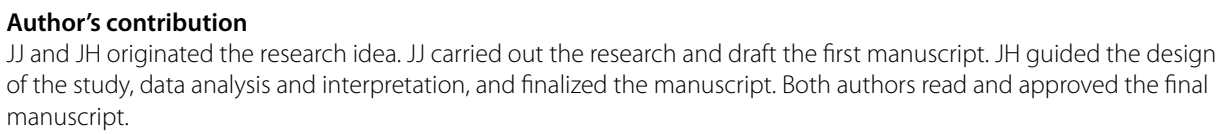

\section{Author details}

1 Department of Fashion Design, Mongolia International University, 13th Khoroo, Bayanzurkh District, Ulaanbaatar, Mongolia. ${ }^{2}$ Department of Textiles, Merchandising and Fashion Design, Seoul National University, 1 Gwanak-ro, Gwanak-gu, Seoul, Republic of Korea.

Competing interests

The authors declare that they have no competing interests.

Consent for publication

Written informed consent was obtained from the paticipants for the publication of this report.

\section{Ethics approval and consent to participate}

This research was conducted in ethical way, under the approval and supervision of Seoul National University Institutional Review Board (IRB Approval No. 1610/001-011) regarding ethical issues in the whole research process.

Funding

None.

\section{Publisher's Note}

Springer Nature remains neutral with regard to jurisdictional claims in published maps and institutional affiliations.

Received: 21 September 2017 Accepted: 2 January 2018

Published online: 28 April 2018

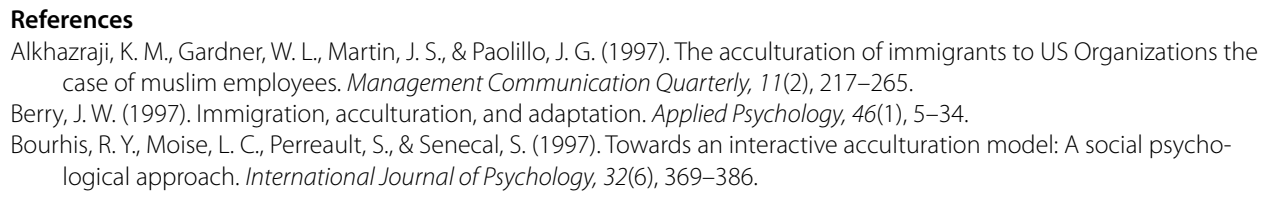


Chae, J. M. (2003). The Mechanisms and patterns of the North Korean defectors' psychological acculturation in the Republic of Korea (Unpublished doctoral dissertation). Seoul: Korea University Graduate School.

Cheng, C. Y. (2000). Acculturation and cultural value orientations of immigrant Chinese Americans: Effects on body image, aesthetics for appearance, and involvement in dress (Unpublished doctoral dissertation). lowa: Iowa State University.

Cho, Y. A., \& Jeon, W. T. (2005). A Qualitative Study of North Korea women defectors' adaptation to South Korean life. The Korean Journal of Woman Psychology, 10(1), 17-35.

Essel, O. Q., \& Kemevor, A. K. (2016). Aesthetical tastes of academical and traditional costumes in academic processions. Fashion and Textiles, 3(1), 1-8.

Forney, J. C. (1980). An investigation of the relationship between dress and appearance and retention of ethnic identity (Unpublished doctoral dissertation). Indiana: Purdue University.

Forney, J. C., \& Rabolt, N. J. (1986). Ethnic identity: Its relationship to ethnic and contemporary dress. Clothing and Textiles Research Journal, 4(2), 1-8.

Ger, G., \& stergaard, P. (1998). Constructing immigrant identities in consumption: appearance among the Turko-Danes. NA-Advances in Consumer Research, 25, 48-52.

Inglessis, M. G. (2008). Communicating through clothing: The meaning of clothing among Hispanic women of different levels of acculturation (Unpublished doctoral dissertation). Florida: The Florida State University.

Jeon, W. T. (1997). A Study on North Korean Defectos' adaptation and self-identity by major background factors. Korean Unification Studies, 1(2), 109-167.

Johnson, K., Lennon, S. J., \& Rudd, N. (2014). Dress, body and self: Research in the social psychology of dress. Fashion and Textiles, 1(20), 1-24.

Jun, D. G. (2015). Value evaluation from immigrant women of international marriage through their cultural identities on Korean women's fashion. Oriental Art, 21, 286-306.

Jung, J., \& Hwang, C. S. (2016). Associations between attitudes toward cosmetic surgery, celebrity worship, and body image among South Korean and US female college students. Fashion and Textiles, 3(17), 1-14.

Keum, M. J. (2015). The trend of research related to North Korean, North Korean refugee, and unification in Korean Psychology: Analysis of researches in 14 Korean Journals of Psychology (2000-2013). Korean Journal of Psychology, 34(2), 541-563.

Kim, M. J. (2004). 복 식미학 강의 1: 복식미를 보는 시각 [Perspectives for dress beauty-lecture on aesthetics in dress I]. Seoul: Kyomunsa.

Kim, M. H. (2016). A Study on North Korean female defectors' clothing life: Actual condition of clothing in North and adaptation process in South (Unpublished Masters' dissertation). Seoul: Korea University Graduate School.

Kwon, K. S. (2016). A Study of Sexual Discourse of the Ruling Power to Govern the Body and Mind of the People: Focusing on the analysis of 『Chosun Nyesung』. The Journal of Korea Culture Technology, 20, 7-44.

Lee, M. K. (2004). Women's Policy of the North Korea through the view of ideal women with contents analysis of 『Chosun Nyesung』. Sino-Soviet Affairs, 28(2), 145-173.

Luedicke, M. K. (2011). Consumer acculturation theory: (crossing) conceptual boundaries. Consumption Markets and Culture, 14(3), 223-244.

Ministry of Unification. (2016a). Policies on North Korean Defectors - Baseline data in June 2016 (Unpublished statistics). Seoul: Ministry of Unification.

Ministry of Unification. (2016b). 독 일 통일 총 서: 통일 교 육 분 야 [Series for the unification of Germany: Policy documents about education after the Unification]. Seoul: Ministry of Unification.

Padilla, A. M., \& Perez, W. (2003). Acculturation, social identity, and social cognition: A new perspective. Hispanic Journal of Behavioral Sciences, 25(1), 35-55.

Park, H. J. (1998). The Case Study on North Korean women defectors' adaptation to the South Korean Society (Unpublished master's dissertation). Kyonggi: The Catholic University of Korea.

Redfield, R., Linton, R., \& Herskovits, M. J. (1936). Memorandum for the study of acculturation. American Anthropologist, 38(1), 149-152.

Rhee, E. Y., Kim, D. S., Park, Y. S., Rhee, K. C., Lee, K. Y., Yi, S. H., et al. (1999). South and North Korean living cultures: Their differences and integration III. Family and Environment Research, 37(1), 15-28.

Rhee, K. C., Lee, K. Y., Rhee, E. Y., Yi, S. H., Park, Y. S., \& Choi, Y. S. (1997a). South and North Korean living cultures: Their differences and integration I. Family and Environment Research, 35(6), 289-315.

Rhee, K. C., Lee, K. Y., Rhee, E. Y., Yi, S. H., Park, Y. S., Kim, D. N., et al. (1997b). Research: South and North Korean living cultures: Their differences and integration (1). Family and Environment Research, 35(6), 289-315.

Sandikci, O., Ekici, A., \& Tari, B. (2006). Consumer acculturation as a dialogical process: case studies from rural-to-urban migrants in Turkey. NA-Advances in Consumer Research, 33, 429-434.

Shim, S., \& Chen, Y. Q. (1996). Acculturation characteristics and apparel shopping orientations: Chinese students and spouses from the People's Republic of China residing in the southwest. Clothing and Textiles Research Journal, 14(3), 204-215.

Sohn, S. H. (2013). North Korean youth defectors' adjustment process as consumers: A Grounded Theory Approach. Journal of Consumer Studies, 24(1), 327-362.

Swaidan, Z., Vitell, S. J., Rose, G. M., \& Gilbert, F. W. (2006). Consumer ethics: The role of acculturation in US immigrant populations. Journal of Business Ethics, 64(1), 1-16.

Upchurch, W. (2008). Relationship between level of acculturation and clothing preferences of Asian-Indian females (Unpublished doctoral dissertation). Alabama: Auburn University.

Warren, C. S. (2008). The influence of awareness and internalization of Western appearance ideals on body dissatisfaction in Euro-American and Hispanic males. Psychology of Men and Masculinity, 9(4), 257.

Warren, C. S., \& Rios, R. M. (2013). The relationships among acculturation, acculturative stress, endorsement of Western media, social comparison, and body image in Hispanic male college students. Psychology of Men and Masculinity, 14(2), 192.

Weinstock, S. A. (1963). Role elements: A link between acculturation and occupational status. The British Journal of Sociology, 14(2), 144-149.

Yen, H. Y., \& Hsu, C. I. (2017). College student perceptions about the incorporation of cultural elements in fashion design. Fashion and Textiles, 4(20), 1-16. 